\title{
CONTRATO DIDÁTICO NO ENSINO REMOTO: UM CONTRIBUTO PARA O ESTUDO DE ÁREA ALIADO AO SOFTWARE GEOGEBRA
}

\author{
CONTRATO DIDÁCTICO EN EDUCACIÓN A DISTANCIA: UNA \\ CONTRIBUCIÓN AL ESTUDIO DEL ÁREA ALIADA AL SOFTWARE \\ GEOGEBRA
}

DIDACTIC CONTRACT IN REMOTE TEACHING: A CONTRIBUTION TO THE STUDY OF AREA ALLIED TO THE GEOGEBRA SOFTWARE

\section{DOI: 10.22481/rbba.v10i02.8869}

Joelma Alves Rodrigues Instituto Federal de Educação, Ciência e Tecnologia do Ceará, Fortaleza, Ceará, Brasil

ID Lattes: http://lattes.cnpq.br/5227607164949949 Endereço eletrônico: joelmaalvesrodrigues2020@gmail.com

Paulo Vitor da Silva Santiago Universidade Federal do Ceará, Fortaleza, Ceará, Brasil

ID Lattes: http://lattes.cnpq.br/9028281383409966 ORCID: http://orcid.org/0000-0002-6608-5452 Endereço eletrônico: pvitor60@hotmail.com

Francisco Régis Vieira Alves Instituto Federal de Educação, Ciência e Tecnologia do Ceará, Fortaleza, Ceará, Brasil

ID Lattes: http://lattes.cnpq.br/3288513376230522 ORCID: http://orcid.org/0000-0003-3710-1561 Endereço eletrônico: fregis@ifce.edu.br

Daniel Brandão Menezes Universidade Estadual Vale do Acaraú, Sobral, Ceará, Brasil ID Lattes: http://lattes.cnpq.br/8450083821283590

ORCID: https://orcid.org/0000-0002-5930-7969

Endereço eletrônico: brandaomenezes@ hotmail.com 


\section{ESTUDO DE ÁREA ALIADO AO SOFTWARE GEOGEBRA}

\section{RESUMO}

$\mathrm{O}$ ensino remoto é aderido em situações emergenciais, nas quais as aulas acontecem fora do espaço físico, a sala de aula, ocorrendo então de forma on-line. O presente trabalho apresenta um modelo de ensino baseado na Teoria das Situações Didáticas (TSD) e amparado pelo software GeoGebra, como forma de facilitar a aprendizagem dos estudantes. Assim, objetiva-se descrever uma proposta didática para $o$ ensino de área de figuras planas, estabelecendo um contrato didático no ambiente remoto. No desenvolvimento, será utilizada a Engenharia Didática (ED) como metodologia de pesquisa, desenvolvendo suas duas primeiras fases (análises preliminares e concepção e análises a priori) e buscando favorecer um ambiente de construção do conhecimento. Um grande desafio para o ensino remoto é o acesso à internet, pois muitos estudantes utilizam uma conexão bastante instável, outros fazem uso dos próprios dados móveis e ainda tem alunos que nem possuem internet em casa, o que, infelizmente, continua sendo um problema em muitas cidades brasileiras.

Palavras-chave: Contrato Didático. Ensino Remoto. Estudo de Área.

\section{RESUMEN}

El aprendizaje a distancia se aplica en situaciones de emergencia, donde las clases tienen lugar fuera del espacio físico, el aula, y luego en línea. Este trabajo presenta un modelo de enseñanza basado en la Teoría de Situaciones Didácticas (TSD) y apoyado en el software GeoGebra, como una forma de facilitar el aprendizaje de los estudiantes. El objetivo es describir una propuesta didáctica para la enseñanza del área de figuras planas, estableciendo un contrato didáctico en el entorno remoto. En el desarrollo se utilizará la Ingeniería Didáctica (DE) como metodología de investigación, desarrollando sus dos primeras fases (análisis preliminar y concepción y análisis a priori), buscando favorecer un entorno para la construcción del conocimiento. Un gran desafío para el aprendizaje remoto es el acceso a internet, ya que muchos estudiantes usan una conexión muy inestable, otros usan sus propios datos móviles y todavía hay estudiantes que ni siquiera tienen internet en casa, desafortunadamente, esto sigue siendo un problema en muchas ciudades brasileñas.

Palabras clave: Contrato didáctico. Enseñanza remota. Estudio de área. 


\begin{abstract}
Remote teaching is adhered to in emergency situations, where the classes take place outside the physical space, the classroom, taking place online. This paper presents a teaching model based on the Theory of Didactic Situations (TSD) and supported by GeoGebra software, as a way to facilitate student learning. It aims to describe a didactic proposal for teaching the area of plane figures, establishing a didactic contract in the remote environment. In the development we will use Didactic Engineering (DI) as a research methodology, developing its first two phases (preliminary analysis and design and a priori analysis), seeking to favor a knowledge construction environment. A major challenge for remote teaching is access to the internet, because many students use a very unstable connection, others use their own mobile data, and there are still students who do not even have internet at home, unfortunately, this is still a problem in many brazilian cities.
\end{abstract}

Keywords: Didactic Contract. Remote Learning. Area Study.

\title{
1. INTRODUÇÃO
}

O cenário educacional em diversos países sofreu alterações em 2020, devido à pandemia da COVID-19, sendo necessária a migração para o ensino remoto, o qual é adotado em situações emergenciais, quando existem fatores que impedem o acontecimento das aulas de forma presencial (CIDRÃO; AZEVEDO; ALVES, 2021). Inclusive, muitos países continuam utilizando essa modalidade de ensino até o momento.

Entretanto, o ensino remoto ainda apresenta muitos desafios na educação brasileira, tanto para os professores, como também para os alunos, isso se dá por diferentes motivos, por exemplo, a formação dos profissionais da área de atuação, acesso à internet, falta de aparelho tecnológico e a difícil compreensão dos conteúdos.

Diante da visão panorâmica e inovadora proporcionada pelo ensino remoto, surge, por meio do triângulo didático (professor, aluno e saber), modelo de sistema didático proposto por Brousseau (1996), uma dinâmica de relações didáticas fora da sala de aula. No ensino presencial, o sistema didático fica restrito ao espaço físico na escola, diferentemente do ensino on-line, o qual apresenta maior complexidade, devido à distância.

\begin{tabular}{l|l} 
Revista RBBA & Revista Binacional Brasil Argentina Vol. 10, num. 2, dez/2021, p. 232-252
\end{tabular} 


\section{ESTUDO DE ÁREA ALIADO AO SOFTWARE GEOGEBRA}

O presente artigo traz, em seu bojo, uma proposta didática relacionada ao contrato didático, desenvolvendo as quatro dialéticas da Teoria das Situações Didáticas (TSD), teoria que estuda as formas de elaboração e apresentação do saber escolar (BROUSSEAU, 1986), e norteada por pressupostos da Engenharia Didática (ED). Será utilizado, durante esse processo, o software GeoGebra, com o objetivo de facilitar o entendimento do aluno referente ao estudo de área de figuras planas.

O contrato didático, criado por Guy Brousseau (1986), é um conceito desenvolvido na Didática da Matemática, representando um acordo para ser cumprido na sala de aula, envolvendo professor, aluno e saber. Segundo Cury (1994, p. 69), “A noção de contrato independe da concepção filosófica ou pedagógica assumida pelo professor, uma vez que é uma relação que se estabelece toda vez que um professor e seus alunos se reúnem em torno de um conhecimento".

Contudo, este trabalho tem como objetivo descrever uma proposta didática que contribua para o estudo de área no ensino remoto, utilizando o contrato didático, por meio da Teoria das Situações Didáticas (TSD) e amparado pelo software GeoGebra. Esse objetivo foi elaborado a partir da Taxonomia de Bloom (1956), que propõe uma classificação dos níveis de aprendizagem.

Utilizou-se, nesta pesquisa, a Engenharia Didática (ED), considerada uma metodologia oriunda de pesquisas referentes à Didática da Matemática, sendo sua principal criadora a Michele Artigue, e serão desenvolvidas suas duas primeiras fases (análises preliminares e concepção e análises a priori). Para Artigue (1988 apud Machado 2002), a Engenharia Didática caracteriza-se como um esquema experimental baseado sobre realizações didáticas em sala de aula, ou seja, sobre a concepção, a realização, a observação e a análise de sequências de ensino. "Essa metodologia pode ser entendida tanto como uma metodologia de pesquisa específica, quanto como uma sequência de aulas ou atividades concebidas e organizadas de forma coerente" (LEIVAS; GOBBI, 2014, p. 184).

Em correlação, segue-se uma sequência de ensino fundamentada na Teoria das Situações Didáticas (TSD), metodologia criada por Brousseau (1986). Essa teoria desmembra o processo de aprendizagem em quatro etapas: ação, formulação, validação e institucionalização.

Nas próximas seções, apresenta-se o contrato didático, Engenharia Didática (ED) e a Teoria das Situações Didáticas (TSD), que darão embasamento teórico a esta investigação.

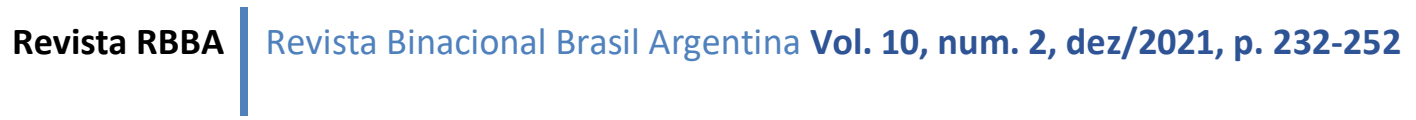




\section{ESTUDO DE ÁREA ALIADO AO SOFTWARE GEOGEBRA}

\section{O CONTRATO DIDÁTICO}

O contrato didático, criado por Guy Brousseau (1986) e, posteriormente, estruturado por Chevallard (1999), é um conceito desenvolvido na Didática da Matemática, na qual agregase nas atividades didáticas, objetivando priorizar o conhecimento matemático.

Nesse sentido, pesquisadores como Brousseau (1986), Cury (1994), Charnay (1996), Chevallard (1999), Beltrão; Souza; Silva (2010) e Cidrão; Azevedo; Alves (2021) utilizaram o contrato didático como referencial teórico em suas pesquisas, este representa, de certa forma, um acordo entre professor e aluno, relacionado ao saber. Esse contrato exprime um conjunto de regras, normalmente implícitas, que ajustam os comportamentos das partes envolvidas, estabelecendo uma relação em torno do conhecimento.

A relação didática entre professor e aluno atua principalmente sob regras implícitas, pois o contrato didático "[...] não pode ser completamente explicitável, uma vez que pretende dizer respeito ao resultado da ação de ensinar" (BROUSSEAU, 1996, p. 52).

O papel implícito no contrato é fundamental para a aprendizagem do aluno, dessa forma, quando o professor não explicita o objeto de estudo, instiga o aluno a construir seu conhecimento, estimulando sua proatividade.

No acordo estabelecido no contrato, presume-se que o aluno desenvolva autonomia para buscar a solução de um problema apresentado, ao invés de ficar esperando uma resposta pronta do seu professor. O professor não embargará a particularidade em assumir as respostas dos problemas matemáticos propostos aos alunos (CHEVALLARD; BOSH; GASCÓN, 2001).

O contrato didático funciona como um meio de comunicação entre docente e discente, proporcionando uma relação à qual se faz necessário estabelecer "[...] um espaço comum de significações entre o professor e os alunos em relação ao saber" (ARRUDA; SOARES; MORETTI, 2003, p. 24).

Como mencionado anteriormente, grande parte do contrato didático é composta por regras implícitas, podendo haver ruptura, isso ocorre quando as regras não são cumpridas, “[...] quando há alguma ruptura do contrato didático na relação, em seguida, uma nova regra (explícita ou implícita) é negociada”. (ALMEIDA; LIMA, 2011, p. 3).

Considerando que existem, no contrato didático, expectativas, rupturas e negociações, apresenta-se no Quadro 1, um resumo dos efeitos que trazem consequências indesejáveis para a relação didática, baseado no trabalho de Almeida e Lima (2011).

Revista RBBA Revista Binacional Brasil Argentina Vol. 10, num. 2, dez/2021, p. 232-252 


\section{ESTUDO DE ÁREA ALIADO AO SOFTWARE GEOGEBRA}

\begin{tabular}{|c|c|}
\hline EFEITOS & DESCRIÇÃO \\
\hline Pigmalião & Expectativa criada pelo professor em relação ao aluno. \\
\hline Topázio & $\begin{array}{c}\text { O professor facilita o milieu de forma que o aluno consiga resolver } \\
\text { um problema, superando as dificuldades. }\end{array}$ \\
\hline Jourdain & $\begin{array}{l}\text { Ocorre quando o professor utiliza estratégias de ensino, evitando } \\
\text { confrontos com o aluno. }\end{array}$ \\
\hline $\begin{array}{l}\text { Deslizamento } \\
\text { metacognitivo }\end{array}$ & $\begin{array}{c}\text { O professor faz uso de explicações como objeto de estudo no lugar do } \\
\text { verdadeiro saber. }\end{array}$ \\
\hline $\begin{array}{l}\text { Uso abusivo de } \\
\text { analogias }\end{array}$ & $\begin{array}{l}\text { Substituição do estudo de uma noção complexa pelo estudo de uma } \\
\text { analogia. }\end{array}$ \\
\hline
\end{tabular}

Quadro 1: Efeitos do contrato didático.

Fonte: Baseado nas ideias de Almeida e Lima (2011).

Esses efeitos são consideráveis no decurso do contrato didático, gerados de conflitos oriundos dos envolvidos, professor e aluno.

Como supracitado, o contrato didático organiza um conjunto de regras entre professor e aluno, relacionado ao saber, em que essas normas devem ocorrer em um ambiente físico, a sala de aula, lembrando que, em algum momento e por algum motivo específico, elas podem ser descumpridas, ocasionando uma ruptura no contrato.

As rupturas são necessárias para que os envolvidos modifiquem a sua relação com o saber em jogo. No ensino remoto, percebe-se uma modificação natural no contrato didático, pois, com a ausência da sala de aula, surge uma alteração na relação do aluno com o saber (CIDRÃO; AZEVEDO; ALVES, 2021). Diante disso, o aluno é instigado a desenvolver sua autonomia para construir seu conhecimento.

De acordo com Moreira e Schlemmer (2020, p. 8), “O Ensino Remoto ou Aula Remota se configura então, como uma modalidade de ensino ou aula que pressupõe o distanciamento geográfico de professores e estudantes", ocorrendo de forma virtual e síncrona. A diferença do ensino presencial é somente a distância entre os envolvidos no processo de ensino e aprendizagem.

Na modalidade de ensino on-line, por conseguinte, o professor passa a ter uma distância no acompanhamento do processo de aprendizagem do aluno, porém, isso não deve ser visto

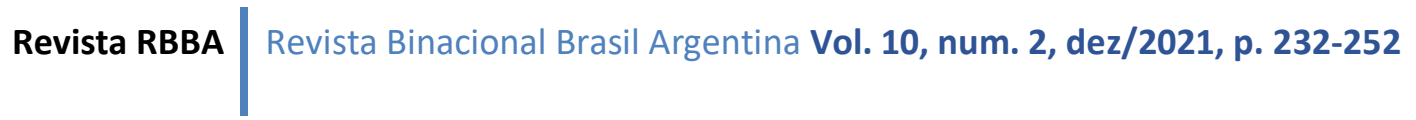




\section{ESTUDO DE ÁREA ALIADO AO SOFTWARE GEOGEBRA}

como um empecilho, uma vez que as regras implícitas e explícitas do contrato didático, nesse contexto, exigem uma dinâmica diferente.

O contrato emite incumbência recíproca e tenciona garantir o conhecimento, no qual o docente deverá impulsionar circunstâncias para que isso aconteça, podendo, o contrato, ser flexível, sendo necessárias mudanças dependendo da situação.

E mesmo perante as mudanças refletidas no ambiente, a relação professor-aluno-saber continua apresentando um papel principal no ensino e na aprendizagem.

\section{ENGENHARIA DIDÁTICA}

A Engenharia Didática (ED) surgiu como metodologia de pesquisa educacional no início da década de 1980, sendo aplicada em trabalhos de Educação Matemática. Machado (2008), realiza uma descrição do trabalho do pesquisador parecido ao de um engenheiro subdividindo suas atividades sem sala de aula, com uso das sequências didáticas. Alves (2017, p. 26) constata que essa metodologia " [...] caracteriza como um esquema experimental baseado num conjunto de experimentações e realizações didáticas em sala de aula.

Nesse contexto, a ED, de Michele Artigue (1996, p. 196), caracteriza como: “[...] metodologia de investigação, caracteriza-se antes de mais nada por um esquema experimental baseado em 'realizações didáticas' na sala de aula, isto é, na concepção, na realização, na observação e na análise de sequências de ensino".

Seguindo o mesmo pensamento, Brousseau (1996, p. 41) retrata na pergunta em que:

[...] medida é esta referência ao funcionamento da investigação necessária e pertinente para o estudo da aprendizagem, e sobretudo do ensino. Até que ponto e em que condições há uma semelhança? Para responder a estas questões, parece serem indispensáveis uma boa teoria epistemológica, acompanhada por uma boa Engenharia Didáctica.

A metodologia está dividida em quatro etapas, seguindo uma sequência nas análises prévias ou preliminares, concepção e análise a priori, experimentação e análise a posteriori e validação.

De acordo com Artigue (1996, p. 198), a primeira fase (análise prévia ou preliminar) inclui uma análise epistemológica do conteúdo do currículo; aprendizagem habitual e seus impactos/consequências; compreensão dos alunos sobre as dificuldades e obstáculos que

Revista RBBA $\quad$ Revista Binacional Brasil Argentina Vol. 10, num. 2, dez/2021, p. 232-252 


\section{ESTUDO DE ÁREA ALIADO AO SOFTWARE GEOGEBRA}

interrompem o seu desenvolvimento; área temática em que serão estabelecidas as metas de execução didática e buscou-se investigar os obstáculos no ensino de área de figuras planas.

A segunda etapa, da concepção e análise a priori, conforme Artigue (1996, p. 202), é a fase que o pesquisador decide como lidar com um certo número de variáveis do sistema que não são fixas, chamadas variáveis de comando, que o pesquisador toma como variáveis importantes para o problema em estudo. A autora também chama a atenção para a distinção entre dois tipos de variáveis de comando: 1) variáveis globais que se relacionam com a organização geral da engenharia; 2) variáveis locais que se relacionam com o encontro ou fase de engenharia, sendo realizadas a generalização e formalização do ensino de área trabalhada em nível local.

Na terceira etapa da ED (experimentação), Artigue (1996, p. 208-209) faz menção ao início que acontece pelo intervalo de aplicação e experimentação das atividades pré-planejadas, coleta de dados sobre o estudo. No segundo momento, refere-se à análise dos resultados que serão alcançados durante o processo de investigação. Essa etapa baseia-se na análise de todos os dados obtidos durante a experimentação ocorridas nas aulas, estabelecendo o contrato didático com a turma perante o encontro virtual e seguindo com a aplicação da sequência didática utilizando a plataforma GeoGebra.

Em sua última etapa (análise a posteriori e validação), todas as informações obtidas durante uma investigação usando questionários, testes, notas de diário de campo, vídeos, produções de alunos ou outras ferramentas apropriadas são levadas em consideração. Nesse sentido, acontece a finalização de um "[...] confronto das duas análises, a priori e a posteriori, que se funda essencialmente a validação das hipóteses envolvidas na investigação" (ARTIGUE, 1996, p. 208). Nesse momento, acontecem os registros perante a plataforma de videoconferência com todos os dados da aplicação.

Em síntese, a ED é descrita pela própria Artigue (1996, p. 193), com o objetivo de propor um método de trabalho didático, para compará-lo com o trabalho de um engenheiro que, para realizar um projeto preciso e meticuloso, se baseia no conhecimento científico da sua área e é obrigado a trabalhar objetos mais complexos do que aqueles refinados pela ciência e, portanto, há a necessidade de estudar de forma prática, usando todos os meios, técnicas e ferramentas disponíveis, sendo estruturado nos problemas aplicados em sala de aula referente ao conteúdo áreas de figuras planas com auxílio da plataforma GeoGebra.

\begin{tabular}{l|l} 
Revista RBBA & Revista Binacional Brasil Argentina Vol. 10, num. 2, dez/2021, p. 232-252
\end{tabular} 


\section{ESTUDO DE ÁREA ALIADO AO SOFTWARE GEOGEBRA}

\section{TEORIA DAS SITUAÇÕES DIDÁTICAS}

A Teoria das Situações Didáticas foi desenvolvida no século XX, na França, por Guy Brousseau, que procurava a estruturação de um ambiente de ensino que conectasse momentos de diálogo entre professor, aluno e saber. Esses diálogos iniciam-se em um meio produzido pelo professor e orientam a aprendizagem do aluno. Pommer descreve a importância do docente e discentes serem mediados pelo saber que define o método como tais acontecimentos irão progredir, e nesse meio, a atuação do professor é fundamental, porque parte dele a seleção do problema, a forma como irá intervir e como deve adequá-lo para que essa tríade seja determinada.

A tríade entre professores, alunos e saberes tem um espaço mais amplo na formação docente, a fim de fornecer aos professores modelos de ensino adequados para valorizar as diferentes formas de apresentação de conteúdos matemáticos aos alunos. De acordo com Alves (2016, p. 137):

[...] (i) tendo em vista sua natureza crifrada, sincopada e de estilo monossêmico, a Matemática exige uma ação de modificação e transformação, levando em consideração o público de interesse; (ii) a natureza dos objetos e processos matemáticos, de per si, podem proporcionar entraves e bloqueios ao ensino; (iii) a natureza dos objetos e processos matemáticos, de per si, podem proporcionar entraves e bloqueios ao aprendizado dos estudantes.

Nesse contexto, apresenta-se a TSD, um modelo desenvolvido pelo matemático francês Guy Brousseau (2008), que permite a compreensão dos relevantes fenômenos trabalhados na aprendizagem matemática em sala de aula e a atuação da tríade, nesse método, ocasionando um significado maior para o discente acerca da importância da disciplina. Para Brousseau (2008, p. 10), a "interação torna-se didática se, e somente se, um dos sujeitos demonstra a intenção de modificar o sistema de conhecimentos do outro (os meios de decisão, o vocabulário, as formas de argumentação, as referências culturais)"”.

O professor utiliza o meio como ferramenta para facilitar a estruturação do conhecimento pelo aluno. Segundo Brousseau (2008), a estrutura ideal para melhor representar a situação didática como ferramenta é o esquema mostrado (Figura 1).

Revista RBBA Revista Binacional Brasil Argentina Vol. 10, num. 2, dez/2021, p. 232-252 


\section{ESTUDO DE ÁREA ALIADO AO SOFTWARE GEOGEBRA}

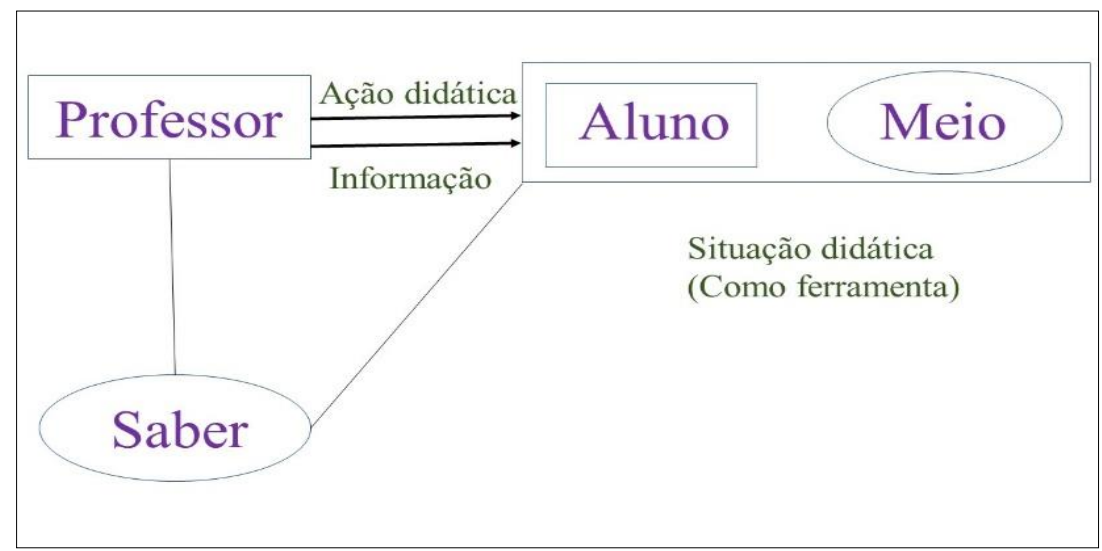

Figura 1: Situação didática como ferramenta.

Fonte: Brousseau (2008, p. 11).

Nessa estrutura, destaca-se o papel do professor:

A intervenção do professor evoca, necessariamente, em relação aos conhecimentos que ensina, um funcionamento possível em outras circunstâncias, não apenas nas "situações com fins didáticos" (exercícios ou problemas) que ele propõe. Cria, então, fictícia ou efetivamente, um outro "meio", em que o aluno atua de forma autônoma (BROUSSEAU, 2008, p. 54).

A análise do diálogo entre os alunos e o milieu (meio) está intimamente ligada ao desenvolvimento do ensino e da aprendizagem, portanto, o ambiente produzirá questionamentos, contradições, ações e emoções, que levarão à aprendizagem da matemática. A posição de Brousseau (2008), no processo de desenvolvimento do conhecimento sobre o papel do professor no ambiente de ensino, precisa ser determinada, o que significa que ela pode nortear a educação no ensino remoto e ser capaz de encontrar problemas que proporcionem essa interação (Figura 1), visualizando o interesse dos alunos, mesmo que a distância seja grande.

Essa busca deve ser estendida à disciplina, como ponto básico de intervenção do professor, a conexão ideal estabelecida pela TSD em resposta à situação.

Segundo Almouloud (2007, p. 17), a teoria das situações didáticas fundamenta-se em três circunstâncias:

(a) O aluno aprende adaptando-se a um milieu que é fator de dificuldade, de contradições, de desequilíbrio, um pouco como acontece na sociedade humana. (b) O professor precisa desenvolver o milieu não munido de intenções didáticas é insuficiente para permitir a aquisição de conhecimentos matemáticos pelo aprendiz. (c) A terceira hipótese postula que esse milieu e essas situações devem engajar fortemente os saberes matemáticos envolvidos no processo de ensino e aprendizagem. 


\section{ESTUDO DE ÁREA ALIADO AO SOFTWARE GEOGEBRA}

A partir dessas circunstâncias, o professor deve preparar um ambiente voltado para o ensino de conteúdos matemáticos, incentivando a aprendizagem e promovendo as atitudes dos alunos diante de uma situação-problema.

Essa preparação Brousseau (1996) relata situações adidáticas, apresenta momentos em que os estudantes constroem de maneira independente, sem a menor interferência do professor no processo de construção da aprendizagem. De fato, Brousseau (1996 apud Silva, Ferreira e Tozetti, 2015, p. 19) estabelece a seguinte organização:

(i) situação didática precisa ter momentos em que o aluno se encontre sozinho diante do problema a resolver, sem a intervenção do professor. Esse momento é considerado como a-didático, uma vez que o aluno deve se relacionar com um problema contando apenas com seus próprios conhecimentos, sentindo-se desafiado pelo problema e não com algum algoritmo pronto e fornecido pelo professor; (ii) o professor não deve intervir diretamente nas opções de solução; (iii) as situações a-didáticas constituem o momento de grande potencialidade justamente por poder vir a romper as condenáveis práticas da repetição e do modelo.

As associações entre as atividades de ensino com o saber matemático na TSD, classificadas em quatro etapas para situações didáticas, divididas em ação, formulação, validação e institucionalização são descritas por Pais (2015):

Situação de ação: é desenvolvida para que o aluno execute procedimentos mais próximos da solução do problema, conduzindo-o à construção de conhecimentos de natureza empírica e instintiva e não teórica.

Situação de Formulação: essa etapa acontece de tal forma que o aluno passa a usar alguma ideia teórica na resolução de uma situação-problema, causando um raciocínio matemático mais dinâmico do que um procedimento empírico e, ao mesmo tempo, é necessário usar a informação para chegar a uma resposta.

Situação de Validação: desenvolvida para que os alunos possam utilizar uma ferramenta de teste, e o conhecimento que já foi estruturado por ela passa a ser utilizado como objetivo teórico. Essa situação está relacionada a um plano de argumentação racional e, portanto, leva à questão da autenticidade do conhecimento.

Situação de Institucionalização: sua utilidade surge na busca de um caráter objetivo e na comunidade de saberes estudada pelo aluno. Pela interação do professor, esse é o momento 
em que segue o caminho para o conhecimento, de um projeto individual e concreto à proporção histórica e cultural do conhecimento científico.

Por ocasião do distanciamento social ocasionado pela COVID-19, levou-se o desenvolvimento da aprendizagem dos sujeitos de forma remota, fazendo-se mudanças na rotina de professores e alunos, sendo uma nova alternativa de ensino matemático. Nesse processo, a aplicação da TSD na disciplina de Matemática acrescentada pela ED utilizou um método qualitativo de investigação no conteúdo de áreas durante a elaboração das situações didáticas aplicadas com foco nas figuras planas, especificamente nas medições de áreas com figuras geométricas planas visando alcançar um quadro de aprendizagem significativa em sala de aula.

\section{METODOLOGIA}

Nesse sentido, acontecem as análises preliminares da ED, em que os pesquisadores se fundamentam com os processos teóricos sobre o conhecimento. Sendo assim, realizou-se uma pesquisa bibliográfica ${ }^{\mathrm{i}}$ envolvendo áreas de figuras planas, baseados pelos autores Ferreira e Oliveira (2018), Charnei (2019) e Costa, Batista e Morais (2019).

\subsection{Análise prévias/preliminares de áreas das figuras planas}

$\mathrm{Na}$ dimensão epistemológica, foram consideradas as origens e o desenvolvimento de conceitos matemáticos relacionados à extensão e generalização das propriedades de áreas de figuras planas. Na dimensão cognitiva, buscam-se métodos que mobilizem o pensamento intuitivo do aluno por meio da situação didática proposta. Do ponto de vista didático, traz uma abordagem baseada na tecnologia para transpor os conceitos matemáticos que possibilitam o ensino desse conteúdo.

Dessa forma, Ferreira e Oliveira (2018, p. 79) descrevem que o "estudo das áreas de figuras planas, tendo em vista sua presença em diversas formas e em variadas situações na nossa vida, seja na natureza, nos objetos que usamos nas artes, nas brincadeiras infantis, nos jogos, nas construções, etc.”. Assim, pode-se relatar que, na exploração das áreas de figuras planas, o estudante desenvolve a percepção das formas geométricas do seu cotidiano, descreve-o, representa-o e compreende a desenvolver-se nele.

Revista RBBA $\mid$ Revista Binacional Brasil Argentina Vol. 10, num. 2, dez/2021, p. 232-252 


\section{ESTUDO DE ÁREA ALIADO AO SOFTWARE GEOGEBRA}

Conforme Charnei (2019), o autor fala da geometria através dos softwares que possibilitam mover as figuras e as alterar, facilitando a modificação de uma experimentação para um pensamento abstrato, ou seja, podem tornar viável a compreensão conceitual dos objetos criados, de forma que não precise de intervenção na edificação de um saber futuro. Apesar dessas tecnologias estarem disponíveis, há possibilidade de experienciar uma conjectura usando várias plataformas e aplicativos e permitir a repetição dos experimentos, devido ao rápido feedback dado pelas tecnologias digitais educacionais.

Nesse sentido, Costa, Batista e Morais (2019, p. 151) retratam que, ao longo do tempo, “o conceito área de figuras planas era explorado nas escolas do Brasil como um tópico do Ensino de Geometria, todavia, essa perspectiva oculta um ponto essencial, que é a abordagem da área como uma grandeza relacionada à figura geométrica”. Dessa forma, considera-se que as grandezas estão relacionadas com os objetos que podem ser comparados a outros idênticos por meio da igualdade das formas geométricas como área, comprimento e o volume incluído no conteúdo de grandezas geométricas.

Segundo Alves (2017), apresenta um estudo teórico-conceitual de um processo sistemático para um acervo de conhecimentos guiados de perspectivas, visando atingir o objetivo desta pesquisa.

\subsection{Concepção e Análise a priori das situações didáticas}

Nessa fase, foram desenvolvidas as situações didáticas para o conteúdo de áreas com figuras planas, em um formato de uma sequência didática, sendo uma lista de atividades: explorando o conceito de áreas com ênfase nas figuras geométricas do quadrado, triângulo, retângulo, losango e trapézio aplicados aos estudantes do Ensino Médio.

A sequência didática é um conjunto de atividades, estratégias e intervenções planejadas passo a passo pelo professor para que a compreensão do conteúdo ou o tema proposto seja alcançada pelos alunos (KOBASHIGAWA et al., 2008). Assim, essa estratégia avançou na assimilação do ensino de áreas com os conceitos voltados para os conhecimentos, permitindo a utilização da plataforma GeoGebra para tirar suas conclusões. Assim, uma ação democrática para os alunos, por meio da sequência de ensino.

Diante disso, a atividade foi realizada em um encontro e destinada a 25 estudantes na faixa etária entre 13 e 15 anos do $1^{\circ}$ ano do ensino médio de uma escola de tempo integral,

Revista RBBA $\mid$ Revista Binacional Brasil Argentina Vol. 10, num. 2, dez/2021, p. 232-252 
localizada no sertão central no estado do Ceará, na disciplina de Matemática em forma remota, e aplicada a partir das etapas da TSD, sendo utilizadas com alunos em um único encontro, tratando sobre áreas, revisando o conceito de figuras planas (Tabela 1).

\begin{tabular}{|c|l|}
\hline Questão 1 & $\begin{array}{l}\text { Seja um triângulo isósceles com altura medindo } 3 \mathrm{~cm} \text { e a base medindo } 4 \mathrm{~cm} . \\
\text { Qual a área desse triângulo? }\end{array}$ \\
\hline Questão 2 & Considere um quadrado com aresta de $4 \mathrm{~cm}$, qual a área deste quadrado? \\
\hline Questão 3 & $\begin{array}{l}\text { Um campo de futebol tem um formato retangular e possui } 5 \text { metros de largura } \\
\text { e } 10 \text { metros de comprimento. Qual a área deste campo de futebol? }\end{array}$ \\
\hline Questão 4 & $\begin{array}{l}\text { Considere um trapézio cuja base menor mede } 4 \mathrm{~cm} \text {, a maior } 6 \mathrm{~cm} \text { e altura de } \\
2 \mathrm{~cm} \text {. Calcule a área desse trapézio. }\end{array}$ \\
\hline Questão 5 & $\begin{array}{l}\text { Seja um losango com a diagonal maior de } 5 \mathrm{~cm} \text { e a menor medindo } 2 \mathrm{~cm} . \\
\text { Qual a área desse losango? }\end{array}$ \\
\hline
\end{tabular}

Tabela 1 - Questões sobre o assunto áreas de figuras planas.

Fonte: Elaborado pelos autores.

A lista com as questões foi disponibilizada no aplicativo de mensagens instantâneas (WhatsApp), sendo nomeada como "Atividade 5 - áreas com figuras planas”, em formato pdf A partir de sua concepção, foi colocado na plataforma de videoconferência o link do GeoGebra, no qual os alunos tiveram a oportunidade de visualizar, construir e manipular as figuras construídas, conforme as instruções da atividade relacionada ao problema, apresentadas na Tabela 1.

Diante disso, a TSD orienta o procedimento, e os estudantes são os sujeitos responsáveis pela construção do seu saber, procurando uma melhor interação por troca de mensagens entre si na plataforma de encontro virtual e com colaboração entre eles para construir os pontos, retas e formas geométricas. O desenvolvimento da aula na plataforma de conversa virtual foi realizado com o conteúdo específico de áreas com uso de figuras planas.

$\mathrm{Na}$ etapa de ação, os estudantes conseguiram analisar as questões de cada problema, realizando primeiro uma leitura de forma concentrada. Com isso, encontraram, em seus conhecimentos preliminares, o conceito de área e suas aplicações em figuras planas.

$\mathrm{Na}$ segunda etapa de formulação, os estudantes depreenderam ideias e começaram a pensar em alguns métodos para o problema, para a partir de então escolher a melhor resposta, e em seguida visualizar o desenho construído na plataforma. Nesse momento, foi disponibilizado um link da plataforma de videoconferência para que os alunos tivessem o acesso

\begin{tabular}{l|l} 
Revista RBBA & Revista Binacional Brasil Argentina Vol. 10, num. 2, dez/2021, p. 232-252
\end{tabular} 
a visualização das questões da plataforma GeoGebra, assim trocando sugestões dentro do ambiente virtual (Figura 2).

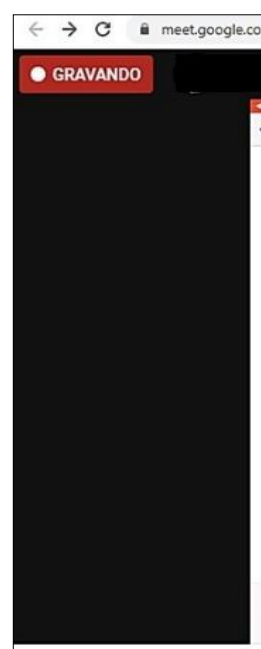

Detalhes da reuniāo $\wedge$

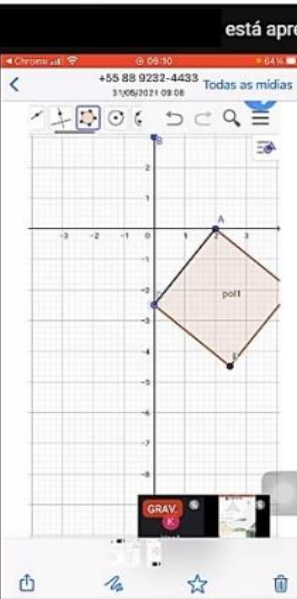

(6)

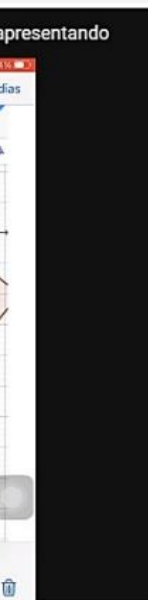

(4)

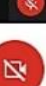

Figura

2.

\section{Plataforma de videoconferência virtual. \\ Fonte: Registro dos autores.}

$\mathrm{Na}$ fase de validação, os alunos buscaram apresentar seus argumentos de forma ordenada, procurando legitimar suas produções acerca das operações de cada área das figuras geométricas. Na Figura 3, mostra-se alguns printscreens das resoluções e construções realizados pelos estudantes.

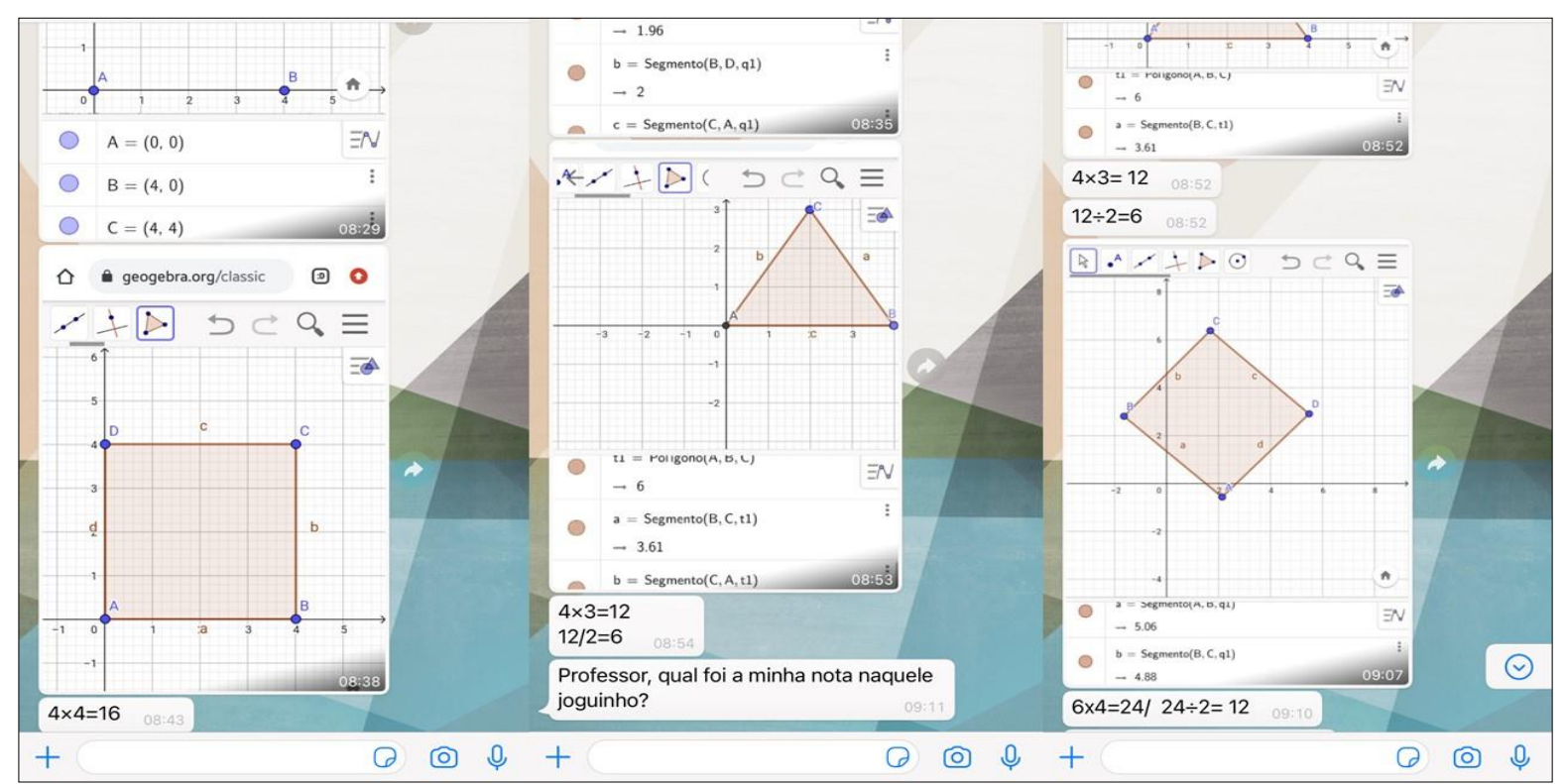

Figura 3. Validação de alguns problemas construídos no GeoGebra com suas resoluções. Fonte: Construções dos estudantes. 
Como se pode visualizar na Figura 3, alguns estudantes enviaram suas resoluções em formato de texto pelo aplicativo de mensagens instantâneas, sendo aqui compartilhado as construções com a resolução utilizando os conceitos de formulação de cada figura exposta. Outros alunos já apresentaram de forma direta os cálculos de área com figuras planas.

\subsection{Experimentação da aplicação}

Nesse momento, o professor mostrou o contrato didático, explicando a todos os sujeitos da pesquisa, em que foi solicitado que os estudantes registrassem suas construções e compartilhassem no final da aula, com a finalidade de promover um ambiente apropriado à aprendizagem. Todos os alunos ficaram cientes de que o professor faria registros da aula em formato de vídeo, fotografias e escritas dentro da plataforma virtual de interação, sem expor a identidade dos envolvidos na atividade prática.

Diante das dificuldades de acesso à internet no ensino remoto, a aplicação da aula aconteceu usando a plataforma de videoconferência virtual e o aplicativo de mensagens instantâneas para o envio das respostas e construções desenvolvidas pelos estudantes.

$\mathrm{Na}$ última etapa de institucionalização, o docente observou as conversas e argumentos apresentados pelos estudantes, verificando sua autenticidade e mostrando como a linguagem matemática formaliza o conceito de áreas. Dessa forma, o aproveitamento adequado da plataforma GeoGebra para o estudo de áreas de figuras planas proporcionou diferentes abordagens de resolução do mesmo problema, observando os elementos matemáticos usados pelos estudantes e suas trocas de informações.

Nessa perspectiva, o professor implementou novos conhecimentos matemáticos para a turma por meio da TSD, a fim e desenvolver seu contexto e autonomia na edificação de conhecimentos para a resolução de situações-problemas de área, a partir da utilização da tecnologia digital educacional, assimilando os raciocínios matemáticos e validação de conjecturas.

\subsection{Análise a posteriori e validação da atividade}

Nessa fase, foram observados os dados obtidos na etapa de experimentação da atividade. Dessa forma, a análise a posteriori se realiza pela extração dos dados durante a fase de

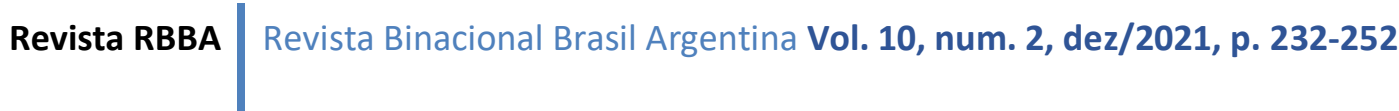




\section{ESTUDO DE ÁREA ALIADO AO SOFTWARE GEOGEBRA}

experimentação. Na experimentação, estabeleceram-se as análises realizadas sobre o processo de ensino, os trabalhos desenvolvidos pela escrita na sala de aula virtual e a troca de ideias durante o momento interativo com turma na videoconferência, levando os aspectos importantes relacionados à investigação deste trabalho.

Nesse momento, foram realizadas duas horas de aula, dividindo o período para uma hora de gravação da aula demonstrativa dos comandos e outra hora para construção dos itens de cada questão atribuída dentro da plataforma GeoGebra.

No momento da Questão 1, os alunos foram instigados sobre a estruturação da figura geométrica do quadrado com a utilização do cálculo de área referente ao problema exposto. Então, eles perceberam que a situação-problema vinha de encontro com a multiplicação dos lados da figura, tendo como resultado o valor total da área do quadrado. A seguir, aconteceu interação virtual entre os estudantes, registrada na plataforma virtual de webconferência, gerando o seguinte diálogo:

Conversação da resolução da Questão 1 com o P1: 31/05/2021 às 8:32 "consegui construir a figura, e agora". P2: 31/05/2021 às 8:40 "fórmula?". P3: $31 / 05 / 2021$ às 8:42 "o meu tá dando certo". P4: 31/05/2021 às 8:46 " $\mathrm{A}=$ b. h assim?". P5: 31/05/2021 às 8:47 "16".

Ao observar as conversas sobre o estudo de área, estes foram relacionados com conhecimentos bases da multiplicação, trabalhados com eles desde o ensino fundamental I e II, indo de encontro ao processo de visualização do comando área da plataforma GeoGebra. Nesse processo da análise a posteriori, seguem-se os resultados obtidos da aplicação dos problemas, analisando aqueles que podem favorecer com a evolução dos conhecimentos didáticos dos estudantes e permitindo o confronto com a análise a priori, em que o docente leva suas análises, estimulando-os a lembrarem das situações-problemas de multiplicação com figuras geométricas. Assim, a execução da atividade com a plataforma Quizizz é mais uma vez fortalecida nesse momento, sendo bastante comunicativa e permitindo o desenvolvimento das cinco questões de área com figuras planas e suas propriedades.

Conforme relata Figueroa e Almouloud (2018), a principal característica da aula é o diálogo entre professores e alunos em que todos têm a oportunidade de participar, alguns respondem, perguntam e outros assistem. Por fim, acredita-se que um bom planejamento e o desenvolvimento de questões interessantes têm um efeito positivo na sala de aula. Para paralelizar o currículo escolar de forma bem articulada, a utilização desse tipo de recurso digital

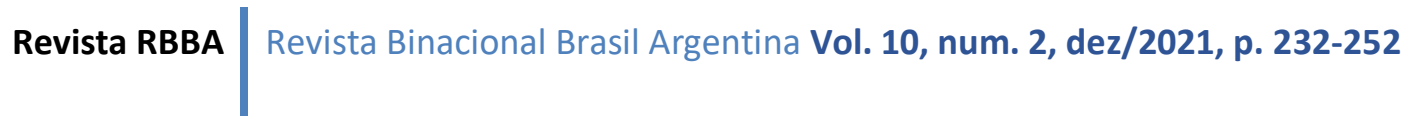




\section{ESTUDO DE ÁREA ALIADO AO SOFTWARE GEOGEBRA}

educacional pode tornar a sala de aula mais dinâmica, gerando interação, interesse e comprometimento dos estudantes.

\section{CONSIDERAÇÕES FINAIS}

Neste trabalho, foi apresentado um modelo de ensino baseado na Teoria das Situações Didáticas (TSD) e amparado pelo software GeoGebra, como forma de facilitar o entendimento dos estudantes, principalmente no que diz respeito à visualização de figuras e à verificação do cálculo de área. O objetivo foi proporcionar uma proposta didática para o ensino de área de figuras planas, estabelecendo um contrato didático no ambiente remoto. De modo geral, a investigação realizada promoveu aos participantes envolvidos, um ambiente interativo e dinâmico.

Durante o desenvolvimento desse estudo, utilizou-se a Engenharia Didática (ED) como metodologia de pesquisa, na qual foram desenvolvidas suas duas primeiras fases (análises preliminares e concepção e análises a priori), descrevendo as quatro dialéticas propostas pela TSD (ação, formulação, validação e institucionalização), buscando favorecer um ambiente de construção do conhecimento.

Com os resultados, houve a percepção de que o contrato didático pode ser utilizado no ensino remoto, o que é incomum na relação didática, contudo, notou-se também que esse contrato serve para analisar o desenvolvimento e o avanço do sistema didático. Além disso, apurou-se que a metodologia, ED, e a teoria, TSD, contribuem consideravelmente para o ensino de matemática, seja para o professor que transmite conhecimentos ou para o aluno que os absorve.

Ademais, o foco esteve em descrever uma proposta didática que contribua para o estudo de área no ensino remoto, utilizando o contrato didático, por meio da Teoria das Situações Didáticas (TSD) e aliado ao software GeoGebra. Perante a isto, afirma-se que houve êxito no objetivo almejado, visto que, concedeu-se subsídios capazes de contribuir positivamente para o aprendizado dos alunos.

No decorrer deste trabalho, o maior desafio encontrado foi o acesso à internet para os estudantes, pois muitos utilizavam uma conexão bastante instável, outros faziam uso dos próprios dados móveis, isso dificultou a comunicação no encontro virtual. Ademais, ainda há

Revista RBBA Revista Binacional Brasil Argentina Vol. 10, num. 2, dez/2021, p. 232-252 


\section{ESTUDO DE ÁREA ALIADO AO SOFTWARE GEOGEBRA}

alunos que nem possuem internet em casa, infelizmente, esse continua sendo um problema em muitas cidades brasileiras.

\section{REFERÊNCIAS}

ALMOUlOUd, S. A. Fundamentos da Didática da Matemática. São Paulo: UFPR, 2007.

ALMEIDA, F. E. L; LIMA, A. P. A. B. Os efeitos do contrato didático na sala de aula de Matemática. In: XIII Conferência Interamericana de Educação Matemática, Recife, PE, p. 1-10, 2011. Disponível em: https://docplayer.com.br/21198306-Os-efeitos-de-contratodidatico-na-sala-de-aula-de-matematica.html. Acesso em: 01 de junho de 2021.

ALVES, F. R. V. Didática da matemática: seus pressupostos de ordem epistemológica, metodológica. Interfaces da Educação, v. 7, n. 21, p. 131-150, 2016.

ALVES, F. R. V. Engenharia Didática com o tema integrais de funções na variável complexa: Análises preliminares, a priori e modelização de situações. Ensino de Ciências e Tecnologia em Revista, v. 7, n. 1, p. 25-48, 2017. Disponível em: https://www.researchgate.net/publication/323668771_ENGENHARIA_DIDATICA_COM_O _TEMA_INTEGRACAO_DE_FUNCOES_NA_VARIAVEL_COMPLEXA_ANALISES_P RELIMINARES_A_PRIORI_E_MODELIZACAO_DE_SITUACOES/link/5aa342ba0f7e9ba dd9a79a24/download. Acesso em: 20 maio 2021.

ARRUDA, J. P.; SOARES, M.; MORETTI; M. T. (Re)Afirmando, (Re)Negociando e (Re)Criando Relações no Ambiente Escolar: a influência do contrato didático no ensino de matemática. Revista PEC, Curitiba, v. 3, n. 1, p. 19-30, 2003. Disponível em $<$ http://www.docstoc.com/docs/20473913/(Re)Afirmando-(Re)Negociando-e(Re)CriandoRela\%C3\%A7\%C3\%B5es-no-Ambiente>. Acesso em: 01 dez. 2010.

ARTIGUE, Michelle. Engenharia didáctica. In: BRUN, Jean (Org.). Didáctica das matemáticas. Tradução de Maria José Figueiredo. Lisboa: Instituto Piaget, p. 193-217, 1996.

BROUSSEAU, Guy. Fondements et méthodes de la didactique des mathématiques. Recherches en Didactique des Mathématiques, v. 7, n. 2, p. 16-33, 1986.

BROUSSEAU, Guy. Fundamentos e métodos da didáctica da matemática. In: BRUN, Jean (Org.). Didáctica das matemáticas. Tradução de Maria José Figueiredo. Lisboa: Instituto Piaget, p. 35 - 113, 1996.

BROUSSEAU, Guy. Introdução ao estudo da teoria das situações didáticas: conteúdos e métodos de ensino. Apresentação: Benedito Antonio da Silva, Consultoria técnica: José Carlos Miguel, Tradução: Camila Bogéa. São Paulo: Ática, 2008.

CHARNEI, M. Dificuldade de aprendizagem do cálculo de área de figuras planas retangulares: uma possibilidade através do GeoGebra. Anais dos Workshops do Congresso Brasileiro de Informática na Educação, [S.1.], p. 623, 2019. Disponível em: <https://www.br- 


\section{ESTUDO DE ÁREA ALIADO AO SOFTWARE GEOGEBRA}

ie.org/pub/index.php/wcbie/article/view/9008>. Acesso em: 31 maio 2021. doi:http://dx.doi.org/10.5753/cbie.wcbie.2019.623.

CHEVALLARD, Y. El análisis de las prácticas docentes en la teoría antropológica de lo didáctico. Recherches en Didactique des Mathématiques, v. 19, n. 2, p. 221-266, 1999.

CHEVALLARD, Y.; BOSH, M.; GASCÓN, J. Estudar matemáticas: o elo perdido entre o ensino e a aprendizagem. Porto Alegre: Artmed Editora, 2001.

CIDRÃO, G. G.; AZEVEDO, I. F.; ALVES, F. R. V. O contrato didático no ensino remoto: uma aplicação na aula de Geometria. Revista Iberoamericana de Tecnología en Educación y Educación en Tecnología, v. 1, n. 28, p. 251-257, 2021.

COSTA, A. P.; BATISTA, R.; MORAIS, M. D. Área de figuras planas no $8^{\circ}$ ano do ensino fundamental do Brasil: um estudo sob a ótica da teoria antropológica do didático. En PérezVera, Iván Esteban; García, Daysi (Eds.), Acta Latinoamericana de Matemática Educativa, v. 32, n. 2, p. 150-158, 2019. Disponível em: http://funes.uniandes.edu.co/14100/. Acesso em: 31 maio 2021.

CURY, H. C. As Concepções De Matemática dos Professores de Matemática e Suas Formas de Considerar os Erros dos Alunos. 1994. 128 f. Tese (Doutorado em Educação) da Universidade Federal do Rio Grande do Sul, Rio Grande do Sul.

FERREIRA, W. C.; OLIVEIRA, C. A. O Scratch nas aulas de matemática: caminhos possíveis no ensino das áreas de figuras planas. Cadernos Cenpec| Nova série, [S.1.], v. 8, n. 1, 2018. Disponível em: <http://cadernos.cenpec.org.br/cadernos/index.php/cadernos/article/view/ 390>. Acesso em: 31 maio 2021. doi:http://dx.doi.org/10.18676/cadernoscenpec.v8i1.390.

FIGUEROA, T. P.; ALMOULOUD, S. A. O Milieu e o Contrato Didático - Análise de uma Aula Demonstrativa do Círculo da Matemática do Brasil. Acta Scientiae, v. 20, n. 4, p. 687706, 2018. Disponível em: http://www.periodicos.ulbra.br/index.php/acta/article/view/4620. Acesso em: 28 maio 2021.

KOBASHIGAWA, A. H.; ATHAYDE, B. A. C.; MATOS, K. F. O.; CAMELO, M. H.; FALCONI, S. Estação ciência: formação de educadores para o ensino de ciências nas séries iniciais do ensino fundamental. In: IV Seminário Nacional ABC na Educação Científica, São Paulo, p. 212-217, 2008 Disponível em: <https://docplayer.com.br/54659874-Estacao-cienciaformacao-de-educadores-para-o-ensino-de-ciencias-nas-series-iniciais-do-ensinofundamental.html>. Acesso em: 31 maio 2021.

LEIVAS, J. C. P.; GOBBI, J. A. O software GeoGebra e a Engenharia Didática no estudo de áreas e perímetros de figuras planas. Revista Brasileira de Ensino de Ciências e Tecnologias, Curitiba, v. 7, n. 1, p. 182-199, 2014.

MACHADO, S. D. A. Engenharia Didática. In: MACHADO, S. D. A. (org). Educação Matemática: Uma (nova) introdução. EDUC 2a ed. São Paulo: [s.n.], p. 197-208, 2002. 
MOREIRA, J. A.; SCHLEMMER, E. Por um novo conceito e paradigma de educação digital online. Revista UFG, v. 20, p. 1-35, 2020.

PAIS, L. C. Didática da matemática: uma análise da influência francesa. Belo Horizonte: Autêntica, 2015.

POMMER, W. M. A Engenharia Didática em sala de aula: Elementos básicos e uma ilustração envolvendo as Equações Diofantinas Lineares. São Paulo: 2013.

SILVA, N. A.; FERREIRA, M. V. V.; TOZETTI, K. D. Um estudo sobre a situação didática de Guy Brousseau. In: XII CONGRESSO NACIONAL DE EDUCAÇÃ̃, Curitiba, v. 12, 2015. Disponível em: https://educere.bruc.com.br/arquivo/pdf2015/18159_8051.pdf. Acesso em: 19 fev. 2021.

\section{NOTAS}

${ }^{\text {i }}$ É a busca de informações bibliográficas, seleção de documentos que se relacionam com o problema de pesquisa como: livros, verbetes de enciclopédia, artigos de revistas, trabalhos de congressos, teses e outros materiais.

ii A sigla inglesa PDF significa Portable Document Format (Formato Portátil de Documento), um formato de arquivo virtual criado pela empresa Adobe Systems para que qualquer documento seja visualizado no formato fixo, independentemente de qual tenha sido o programa que o originou. 